\title{
$\begin{array}{ll}\text { Research Square } & \text { Preprints are preliminary reports that have not undergone peer review. } \\ \text { They should not be considered conclusive, used to inform clinical practice, }\end{array}$
}

\section{Alcohol consumption and associated risk factors in Burkina Faso: results of a population-based cross- sectional survey.}

Bruno Bonnechère ( $\sim$ bbonnech@ulb.ac.be)

Universite Libre de Bruxelles Faculte de Medecine https://orcid.org/0000-0002-7729-4700

\section{Sékou Samadoulougou}

Institut universitaire de cardiologie et de pneumologie de Quebec

\section{Kadari Cissé}

Institut de recherche en sciences de la santé

\section{Souleymane Tassembedo}

Centre MURAZ

\section{Séni Kouanda}

Institut de recherche en sciences de la santé

\section{Fati Kirakoya-Samadoulougou}

Universite Libre de Bruxelles Ecole de Sante Publique

\section{Research article}

Keywords: Alcohol consumption, Abusive alcohol consumption, Burkina Faso, Risk factors, Surveillance, WHO STEPS survey

Posted Date: October 28th, 2020

DOl: https://doi.org/10.21203/rs.3.rs-36027/v2

License: (9) This work is licensed under a Creative Commons Attribution 4.0 International License.

Read Full License

Version of Record: A version of this preprint was published at BMJ Open on February 1st, 2022. See the published version at https://doi.org/10.1136/bmjopen-2021-058005. 


\section{Abstract}

Background: Lifestyle modifiable risk factors are a leading preventable cause of non-communicable diseases (NCDs). Amongst them, alcohol and tobacco consumption are the most important. Studies characterizing the prevalence of alcohol consumption in low-income countries are lacking. This study describes the prevalence of alcohol use in Burkina Faso and its associated factors separately for urban and rural residents.

Methods: Data from the 2013 Burkina Faso World Health Organization (WHO) Stepwise approach to Surveillance (STEPS) were analyzed. The prevalence of alcohol consumption over the last 30 days were recorded and recoded into categories according to WHO recommendations: low alcohol consumption ( $<40 \mathrm{~g}$ alcohol/day for men, $<20 \mathrm{~g}$ for women), mid alcohol consumption (between 40 and $59.9 \mathrm{~g} /$ day for men and between 20 and $39.9 \mathrm{~g}$ for women) and a heavy consumption ( $>60 \mathrm{~g} /$ day for men and $40 \mathrm{~g}$ for women). Logistic regression analyses identified factors associated with alcohol consumption use.

Results: In the whole population 3,559 (75.8\% [72.5 - 78.7]) were not consuming any alcohol, 614 (12.9\% [10.9 - 15.3]) had a low alcohol consumption, 399 (8.5\% [7.1 - 10.1]) a mid alcohol consumption and $120(2.7 \%$ [2.0 - 3.7]) a high consumption. Age was associated with alcohol intake with a gradient effect, older people having a higher risk $(A O R=2.31[1.68-3.17]$ for the $55-64$ years old compared to $25-34$ group). Tobacco consumption was also significantly associated with alcohol intake with a gradient effect, those with higher tobacco consumption being at higher risk of abusive alcohol intake. When analyzing the risk of having abusive consumption in those consuming alcohol, we found a highly significant gender effect, with males having an increased risk (AOR $=2.53[1.38-4.68]$ ).

Conclusion: Our data showed an important burden of alcohol consumption in Burkina Faso with a strong relationship with age, gender and tobacco consumption and disparities across the different regions of Burkina Faso. To effectively reduce alcohol consumption in Burkina Faso, a comprehensive control program should consider these associated factors.

\section{Background}

The increase in life expectancy [1] combined with unhealthy behaviors and physical inactivity [2] are linked to a rise in non-communicable diseases (NCDs) such as cardiovascular disease, cancer, chronic respiratory disease, and diabetes [3]. Currently, the leading causes of ill health in the world, NCDs account for seven out of ten deaths worldwide [4].

Low and mid-income countries are facing the emergence of non-communicable diseases (NCDs) [5]. Although some risk factors have been identified such as high blood pressure [6], lack of physical activity [7], inadequate diet [8], etc., there is still a lack of comprehensive data on other modifiable risk factors, in particular tobacco and alcohol consumption [9], in Burkina Faso. 
Recently, clear evidence of increased alcohol consumption and attributable harm in many low and midincome countries has been highlighted [10]. Furthermore, it is predicted to have a more harmful effect if effective policy is not adopted [11]. Currently, the prevalence of alcohol intake among the African adult population is about $30 \%$ [12], which is lower compared to the rest of the world where $40 \%$ of the world's adult population consumes alcohol and the average consumption per drinker is 17.1 liters per year. Interestingly, the prevalence of lifetime abstention, the level of alcohol consumption, and the drinking patterns vary widely across regions of the world [13]. For exemple Eastern Europe and Southern Africa had the most detrimental pattern of drinking scores. At the same time, Europe (Eastern and Central) and sub-Saharan Africa (Southern and West) are the most important consumers of alcohol [13]. In Africa, among current drinkers, the prevalence of heavy drinking varied between $7 \%$ and $77 \%$ and the prevalence of daily light drinkers varied between $0 \%$ and $21 \%$. Overall, drinking patterns varied significantly between and within the examined African countries [14].

One of the major current concerns related to alcohol consumption in Africa is that alcohol companies have targeted Africa as a new market. With the expected increases in the number of potential new alcohol consumers, especially young people and women, the African continent has indeed been identified by the alcohol beverage industry and market researchers as a key area for alcohol market growth $[15,16]$. It is, therefore, of particular importance to identify subjects the most at risk of alcohol consumption. Currently, two major risk factors have been identified worldwide: gender with the male being more at risk [17] and the socioeconomic level where the effect is less clear as the associations between socioeconomic disadvantage and heavier drinking vary depending on country-level income [18]. A group that is particularly at risk because of the vulnerability of the fetus is the pregnant women [19-21]. There is currently a lack of information about the prevalence of alcohol consumption in Burkina Faso and the associated risk factors. Differences in cultural factors (e.g., beliefs and practices) may influence health status, but social, economic, and structural determinants of health during people's lifespans appear to be associated with health inequities between ethnic groups as well. Therefore, cultural influences should not be overemphasized as discrete explanatory factors for health inequities [22].

A first national survey was conducted in 2013 using the WHO STEPwise approach to risk factors surveillance (STEPS). The STEPS survey is a simple, standardized method for collecting, analyzing, and disseminating data in WHO member countries. It covered a representative sample of the adult populations. The first analyses performed were about the evaluation of cardiovascular risk [23]. In a previous study, we show that tobacco consumption was highly correlated with alcohol consumption in men [24]. Therefore, the aim of this study is to study the prevalence of alcohol consumption and their associated risk factors. Such kind of analysis is needed in order to drive more efficient prevention campaigns for both alcohol and tobacco consumption.

\section{Methods}

\section{Study settings}


Burkina Faso is a landlocked country in West Africa of $272967.47 \mathrm{~km}^{2}$. In 2020, the population was estimated at $20,903,273$ inhabitants. The majority of the population $(77.30 \%)$ lives in rural areas and rely on agriculture and livestock as main source of income [25].

The median age of the population is 17.9 years old. The total fertility rate is 5.2 (2018) and the life expectancy at birth was 62.3 years in 2019. As most of the low-income countries, Burkina Faso must face the double burden of infectious and chronic diseases. The country is regularly confronted with outbreaks such as measles, cerebrospinal meningitis and, malaria [26], while NCDs constitute a raising public health problem with only limited financial resources allocated.

In Burkina Faso, several sources of alcohol manufacturing exist: modern brewery and legally imported alcohol, prohibited alcohol mostly imported from neighboring countries and traditional beer manufacturers. Burkina Faso is a laic country with almost more than half of the population declared as being of Islamic faith.

Harmful alcohol use and its adverse events (i.e., road traffic accidents) is however an important and raising public health concerns in Burkina Faso [27].

\section{Study design}

This is an analytical cross-sectional study. The database collected during the baseline data of the WHO STEPS survey conducted in Burkina Faso in 2013 was used in this study. Complete details on the methodology and sampling procedure were described in the WHO STEPS 2013 Burkina report [28], and in previous studies using this database $[23,24,29]$. Briefly, the participants were selected using a threestage cluster sampling process involving the selection of clusters, households, and individuals.

The protocol of the STEPS survey was reviewed and approved by the Ethics Committee for Health Research of the Ministry of Health, which gave clearance in accordance with regulations in force (Deliberation No. 2012-12- 092 of 05 December 2012). Written informed consent was systematically sought and obtained from all participants before inclusion in the study. The confidentiality of study participants was fully respected and the analyses performed did not identify any participant.

\section{Study population}

Participants of the study were adults of both sexes aged 25 to 64 years old who had been living in Burkina Faso for at least six months. Exclusion criteria were: people with disabilities hampering their ability to answer the questions (e.g., intellectual disabilities, serious mental disorders, cognitive impairment, etc.).

\section{Sampling}


The STEPS survey of Burkina Faso was conducted on a representative sample of 4,800 individuals, the response rate of the STEPS survey was $99.1 \%$ in Burkina Faso [26]. The sample size is estimated using the following Schwartz formula: $n \geq \operatorname{deff} \frac{z_{\alpha}^{2} p(1-p)}{\varepsilon^{2}} * s u b /(1-t)$ for p (high blood pressure prevalence previously estimated at $29.3 \%$; deff design effect fixed at 1.5, $\varepsilon$ absolute error (5\%); $z_{\alpha}$ fractile of normal distribution of $5 \%$ error (1.96)) [26]. The sample calculation was adjusted to account for a subgroup analysis of eight subgroups (sub) (four age groups, and two gender or two residence groups) and for a non-response rate (t) of $20 \%$. After excluding participants with missing information about sampling weight, 4,692 individuals were included in the present analysis. The diagram flow of study participants is presented in Figure 1.

The study's sampling frame was based upon enumerations (EAs) from the 2006 general census of the population and housing (GCPH) and updated in 2010 during the Demographic and Health Survey in Burkina Faso. In the first stage, geographic areas were stratified into rural and urban, and EAs were selected with probability proportional to their size from both strata. A total of 240 EAs were selected: 185 from rural areas and 55 from urban areas. In the second stage, 20 households were selected from each EA. In the third stage, one person aged from 25 to 64 years in each household was selected using the Kish method.

\section{Data collection}

The STEPS questionnaire is made up of several modules that include demographic information, anthropometric measures, and behavioral measurement. A full description of the study design and the data collection has been published elsewhere $[23,29]$. Briefly, All data on alcohol consumption were collected using a standardized questionnaire during face-to-face interviews in the language most spoken by the respondent. The questionnaires was pre-tested on the field before being used for the national survey. Alcohol consumption was assessed with the question 'Have you ever consumed any alcohol such as beer, wine, spirits or dolo'? If the answer is yes, the current alcohol consumption was assessed with the questions 'During the past 30 days, how many days did you consume alcohol drinks?' and 'When you are 
drinking, what is the average number of drinks ?'. Four levels were defined: no consumption, low, mid, and abusive consumption (see Table 1 for WHO definition).

Table 1: Definition of recoded exposure variables.

\begin{tabular}{|l|l|}
\hline Variables & Categories \\
\hline Age groups & $\begin{array}{l}\text { "25 to } 34 \text { years old", "35 to } 44 \text { years old", "45 to 54 years old", } \\
\text { "55 to } 64 \text { years old" }\end{array}$ \\
\hline Education & "None", "Primary", "Secondary", "Tertiary" \\
\hline Marital status & "Single", "Married", "Divorced/widowed" \\
\hline Occupational status & "Wage earner", "Self-employed", "Jobless", "Housemaker" \\
(WHOcomol consumption & $\begin{array}{l}\text { None: Never intake of alcohol } \\
\text { Low: intake of an average quantity of pure alcohol of less than } \\
40 \text { g per day for men and less than } 20 \text { g for women } \\
\text { Mid: corresponds to taking an average quantity of pure alcohol } \\
\text { of between } 40 \text { g and } 59.9 \text { g per day for men and between } 20 \mathrm{~g} \\
\text { and } 39.9 \text { g for women } \\
\text { Abusive: intake of an average quantity of pure alcohol greater } \\
\text { than or equal to } 60 \text { g per day for men and greater than or equal } \\
\text { to } 40 \text { g for women. }\end{array}$ \\
\hline
\end{tabular}

Note than one glass of alcohol (beer, wine, 'dolo') contains $10 \mathrm{~g}$ of ethanol, the recall period is 30 days.

\section{Study variables}

The dependent variable was the mean alcohol consumption in the last 30 days. First, we analyzed alcohol consumption to define the profile of the drinker. Then we identify the profile of the abusive consumer, following WHO recommendations [30], amongst current drinkers.

The independent variables were: age, sex, education, marital status, occupational status and tobacco consumption.

\section{Data analysis and processing}


Some independent quantitative variables were transformed into categorical variables. The list of the variables with the recoded variables is presented in Table 1. Qualitative variables were described using proportions. The Chi-squared test was used in univariable analysis to test the association between the outcome and the categorical variables. Multivariable analysis was then performed: we used a logistic regression model fitted using stepwise backward regression modeling. We first analyzed the profile of alcohol consumption using ordinal logistic regression. Then to analyze the risk of abusive consumption among drinkers, we performed a second analysis using logistic regression grouping low and mid consumption as reference.

Crude and adjusted ORs were calculated for the studied variables and presented with $95 \%$ confidence intervals. We then analyzed discrepancies between the different regions using adjusted ORs for the different regions.

All the analyses were carried out using the survey function with the sampling weight option to account for the sampling design.

Statistics have been conducted in STATA (version 13), RStudio (version 1.1.442) with R version 3.4.4 and QGIS (version 2.18.19).

\section{Results}

Characteristics of the population are presented in Table 2. Most of the participants were rural residents (79.7\%). The population was predominantly young, with the 25-34 years group representing $41.9 \%$. Women were a bit more represented, with $54.3 \%$ of the total sample. Concerning the comparison between urban and rural residents there is no difference in term of age $\left(\chi^{2}(3)=2.36, p=.51\right)$, $\operatorname{sex}\left(\chi^{2}(1)=3.71, p=\right.$ $.054)$, but there are statistically significant differences for the educational level $\left(\chi^{2}(2)=924, p<.001\right)$, the marital status $\left(\chi^{2}(2)=233, p<.001\right)$, the occupational status $\left(\chi^{2}(3)=810, p<.001\right)$.

Table 2: Socio-demographic characteristics of the study sample and prevalence of alcohol and abusive alcohol consumption 


\begin{tabular}{|c|c|c|c|}
\hline Variables & $\begin{array}{l}\text { Participants, } \\
\text { n (\%) }\end{array}$ & $\begin{array}{c}\text { Alcohol consumption } \\
{[95 \% \mathrm{CI}]}\end{array}$ & $\begin{array}{c}\text { Abusive alcohol consumption, } \\
\%[95 \% \mathrm{CI}]\end{array}$ \\
\hline \multicolumn{4}{|c|}{ Age groups, years $(n=4,692)$} \\
\hline 25 to 34 years & $2,124(42.0)$ & $19.5[16.5-22.9]$ & $2.3[1.5-3.6]$ \\
\hline 35 to 44 years & $1,181(27.9)$ & $25.1[21.4-29.3]$ & $3.9[2.4-6.3]$ \\
\hline 45 to 54 years & $841(18.6)$ & $28.1[23.4-33.3]$ & $4.9[3.1-8.0]$ \\
\hline 55 to 64 years & $546(11.5)$ & $32.7[26.4-39.6]$ & $4.3[2.0-8.8]$ \\
\hline \multicolumn{4}{|l|}{$\operatorname{Sex}(n=4,692)$} \\
\hline Female & $2,436(54.3)$ & $20.4[17.1-24.0]$ & $1.1[0.6-1.9]$ \\
\hline Male & $2,256(45.7)$ & 28.8 [25.1 - 32.7] & $6.4[4.4-9.0]$ \\
\hline \multicolumn{4}{|c|}{ Living environment $(\mathrm{n}=4,692)$} \\
\hline Urban & $945(24.9)$ & $27.1[21.8-32.9]$ & $5.6[3.3-9.2]$ \\
\hline Rural & $3,747(75.1)$ & $23.3[19.8-27.1]$ & $2.8[1.9-4.0]$ \\
\hline \multicolumn{4}{|c|}{ Education (n = 4,684) } \\
\hline None & $3,622(77.3)$ & $22.0[18.7-25.7]$ & $2.5[1.7-3.7]$ \\
\hline Primary & $728(15.3)$ & $28.0[23.3-33.2]$ & $4.7[2.7-8.2]$ \\
\hline Secondary & $334(7.3)$ & $39.3[31.8-47.2]$ & $11.9[6.4-21.1]$ \\
\hline \multicolumn{4}{|c|}{ Marital status $(n=4,688)$} \\
\hline Single & $333(6.8)$ & $31.4[23.5-40.5]$ & $7.1[3.4-13.9]$ \\
\hline Married & $4,043(87.2)$ & $23.5[20.4-26.9]$ & $3.1[2.2-4.3]$ \\
\hline Divorced/Widowed & $311(5.9)$ & $26.7[20.8-33.7]$ & $4.9[2.2-10.8]$ \\
\hline \multicolumn{4}{|c|}{ Occupational status $(n=4,692)$} \\
\hline Wage earner & $281(6.3)$ & $37.8[31.3-44.6]$ & $13.6[8.2-21.9]$ \\
\hline Self-employed & $3,249(66.4)$ & $24.1[20.7-27.8]$ & $3.8[2.6-5.5]$ \\
\hline Jobless & $125(2.9)$ & $22.8[15.3-32.4]$ & $0.6[0.1-4.4]$ \\
\hline Housemaker & $1,037(24.5)$ & $21.2[16.4-27.1]$ & $0.5[0.1-1.8]$ \\
\hline \multicolumn{4}{|c|}{ Tobacco consumption $(\mathrm{n}=4,692)$} \\
\hline No & $4,217(90.8)$ & $22.7[19.6-26.0]$ & $2.7[1.9-3.7]$ \\
\hline$<5$ cigs/day & $210(3.8)$ & $32.2[25.0-40.4]$ & $8.7[4.3-16.7]$ \\
\hline $5-10$ cigs/day & $184(3.6)$ & $40.3[32.0-49.1]$ & $10.0[4.9-19.2]$ \\
\hline$>10$ cigs/day & $81(1.7)$ & $51.8[36.2-67.1]$ & $24.3[7.7-55.5]$ \\
\hline
\end{tabular}

Alcohol consumption include the different level of consumption (low-mid and abusive)

In the whole population 3,559 (75.8\% [72.5 - 78.7]) were not consuming any alcohol, $614(12.9 \%$ [10.9 15.3]) had a low alcohol consumption, 399 (8.5\% [7.1 - 10.1]) a mid alcohol consumption and $120(2.7 \%$ [2.0 - 3.7]) an abusive consumption. There are important differences between the different regions of the countries; results are presented in Figure 2. In the Sahel region the prevalence is null while in the SudOuest regions the prevalence for all the levels are statistically significantly higher than the country's average values.

The prevalence of abusive consumption was not different in urban setting and rural setting $(4.3 \%$ [2.5 7.3] versus $2.1 \%$ [1.5 - 3.1], $p=.19$ ) but the prevalence was higher in urban setting for heavy and moderate consumption (14.3\% [12.1 - 16.5] versus 10.1\% [9.1 - 11.1] respectively, $p=.003)$. The repartition of consumption was statistically significantly different between urban and rural environment 
$(p=.001)$ : There were a higher proportion of low alcohol consumption is rural area ( $13.3 \%$ compared to $11.8 \%)$ while in urban area there is more mid $(11.4 \%$ Vs. $7.7 \%)$ and high consumption $(3.1 \%$ Vs. $2.4 \%)$.

In a multivariable analysis (Table 3 ), first concerning the alcohol consumption there is a statistically significant gradient effect of the age $(A O R=1.52$ [1.24 - 1.87], 1.88 [1.49 - 2.36] and 2.31 [1.68 - 3.17] for the 35-44, 45-54 and 55-64 years old respectively compared to the 25-34 years old group). There is also an important gradient effect associated with tobacco consumption (AOR = 3.88 [1.74 - 8.67] for subjects smoking more than 10 cigarettes per day). Another risk factor is the education level ( $A O R=1.47$ [1.13 - 1.91] and $2.60[1.47-4.58]$ for primary and secondary levels respectively, compared to no education).

Table 3: Factors associated with alcohol and abusive alcohol consumptions in population aged 25 - 64 years. 


\begin{tabular}{|c|c|c|c|c|c|c|}
\hline \multirow[t]{2}{*}{ Variables } & \multicolumn{3}{|c|}{ Alcohol consumption } & \multicolumn{3}{|c|}{ Abusive alcohol consumption } \\
\hline & $\mathrm{N}$ & COR $(95 \% \mathrm{CI})$ & AOR $(95 \% \mathrm{CI})$ & $\mathrm{n}$ & $\begin{array}{c}\text { COR } \\
(95 \% \mathrm{CI})\end{array}$ & $\begin{array}{c}\text { AOR } \\
(95 \% \mathrm{CI})\end{array}$ \\
\hline \multicolumn{7}{|l|}{ Age groups } \\
\hline $\begin{array}{c}25 \text { years to } 34 \\
\text { years }\end{array}$ & 413 & \multicolumn{2}{|c|}{1} & 41 & \multicolumn{2}{|c|}{1} \\
\hline $\begin{array}{c}35 \text { years to } 44 \\
\text { years }\end{array}$ & 303 & $\begin{array}{c}1.38[1.12- \\
1.72]^{* *}\end{array}$ & $\begin{array}{c}1.52[1.24- \\
1.87]^{* * *}\end{array}$ & 30 & $\begin{array}{c}1.26(0.68- \\
2.33)\end{array}$ & $\begin{array}{c}1.55(0.84- \\
2.86)\end{array}$ \\
\hline $\begin{array}{c}44 \text { years to } 54 \\
\text { years }\end{array}$ & 234 & $\begin{array}{c}1.61[1.28- \\
2.02]^{* * *}\end{array}$ & $\begin{array}{c}1.88[1.49- \\
2.36]^{* * *}\end{array}$ & 30 & $\begin{array}{c}1.41(0.74- \\
2.69)\end{array}$ & $\begin{array}{c}1.91(0.95- \\
3.85)\end{array}$ \\
\hline 55 to 64 & 179 & $\begin{array}{c}1.94[1.43- \\
2.63]^{* * *}\end{array}$ & $\begin{array}{c}2.31[1.68- \\
3.17]^{* * *}\end{array}$ & 19 & $\begin{array}{l}0.93(0.40- \\
2.16)\end{array}$ & $\begin{array}{c}0.99(0.38- \\
2.57)\end{array}$ \\
\hline \multicolumn{7}{|l|}{ Sex } \\
\hline Female & 496 & \multicolumn{2}{|c|}{1} & 22 & \multicolumn{2}{|c|}{1} \\
\hline Male & 633 & $\begin{array}{c}1.50[1.23- \\
1.83]^{* * *}\end{array}$ & $\begin{array}{c}1.17[0.91- \\
1.52]\end{array}$ & 98 & $\begin{array}{c}4.28(2.30- \\
7.81)^{* * *}\end{array}$ & $\begin{array}{c}2.53(1.38- \\
4.68) * *\end{array}$ \\
\hline \multicolumn{7}{|l|}{ Living environment } \\
\hline Urban & 250 & \multicolumn{2}{|c|}{1} & 30 & \multicolumn{2}{|c|}{1} \\
\hline Rural & 879 & $\begin{array}{c}0.78[0.56- \\
1.10]\end{array}$ & $\begin{array}{c}1.08[0.71- \\
1.64]\end{array}$ & 90 & $\begin{array}{c}0.55(0.26- \\
1.13)\end{array}$ & $\begin{array}{c}0.68(0.34- \\
1.36) \\
\end{array}$ \\
\hline \multicolumn{7}{|l|}{ Education } \\
\hline None & 814 & & & 81 & \multicolumn{2}{|c|}{1} \\
\hline Primary & 198 & $\begin{array}{c}1.37[1.07- \\
1.75]^{*}\end{array}$ & $\begin{array}{c}1.47[1.13- \\
1.91]^{* *}\end{array}$ & 19 & $\begin{array}{c}1.47(0.70- \\
3.04)\end{array}$ & $\begin{array}{c}0.89(0.43- \\
1.86)\end{array}$ \\
\hline Secondary & 114 & $\begin{array}{c}2.46[1.63- \\
3.72]\end{array}$ & $\begin{array}{c}2.60[1.47- \\
4.58]^{* * *}\end{array}$ & 19 & $\begin{array}{c}2.64(1.27- \\
5.50)^{*}\end{array}$ & $\begin{array}{c}1.25(0.48- \\
3.25)\end{array}$ \\
\hline \multicolumn{7}{|l|}{ Marital status } \\
\hline Single & 105 & \multicolumn{2}{|c|}{1} & 17 & \multicolumn{2}{|c|}{1} \\
\hline Married & 930 & $\begin{array}{c}0.67[0.44- \\
1.01] \\
\end{array}$ & $\begin{array}{c}0.68[0.44- \\
1.03] \\
\end{array}$ & 93 & $\begin{array}{c}0.58(0.29- \\
1.16)\end{array}$ & $\begin{array}{c}0.70(0.32- \\
1.53) \\
\end{array}$ \\
\hline Divorced/Widowed & 94 & $\begin{array}{c}0.84[0.53- \\
1.32]\end{array}$ & $\begin{array}{c}0.75[0.45- \\
1.26]\end{array}$ & 10 & $\begin{array}{c}0.82(0.26- \\
2.56)\end{array}$ & $\begin{array}{c}1.41(0.45- \\
4.46)\end{array}$ \\
\hline \multicolumn{7}{|l|}{ Occupational status } \\
\hline Wage earner & 102 & \multicolumn{2}{|c|}{1} & 20 & \multicolumn{2}{|l|}{1} \\
\hline Self-employed & 777 & $\begin{array}{c}0.48[0.34- \\
0.68]^{* * *}\end{array}$ & $\begin{array}{c}0.85[0.58- \\
1.27]\end{array}$ & 4 & $\begin{array}{c}0.40(0.19- \\
0.82)\end{array}$ & $\begin{array}{c}0.51(0.19- \\
1.50)\end{array}$ \\
\hline Jobless & 32 & $\begin{array}{c}0.44[0.24- \\
0.80]^{* *}\end{array}$ & $\begin{array}{c}0.53[0.28- \\
0.99]\end{array}$ & 95 & $\begin{array}{l}0.06(0.01- \\
0.48)^{* *}\end{array}$ & $\begin{array}{l}0.05(0.01- \\
0.47)^{* *}\end{array}$ \\
\hline House maker & 218 & $\begin{array}{c}0.41[0.28- \\
0.61]^{* * *}\end{array}$ & $\begin{array}{c}0.95[0.58- \\
1.56]\end{array}$ & 1 & $\begin{array}{c}0.05(0.01- \\
0.24)^{* * *}\end{array}$ & $\begin{array}{c}0.14(0.02- \\
0.78) *\end{array}$ \\
\hline \multicolumn{7}{|c|}{ Tobacco consumption } \\
\hline No & 952 & \multicolumn{2}{|c|}{1} & 86 & \multicolumn{2}{|c|}{1} \\
\hline$<5$ cigs/day & 67 & $\begin{array}{c}1.51[1.08- \\
2.09]^{*}\end{array}$ & $\begin{array}{c}1.52[1.08- \\
2.15]^{*}\end{array}$ & 14 & $\begin{array}{c}2.37(1.02- \\
5.50) *\end{array}$ & $\begin{array}{c}1.71(0.68- \\
4.26)\end{array}$ \\
\hline 5 - 10 cigs/day & 70 & $\begin{array}{c}2.30[1.57- \\
3.36]^{* * *}\end{array}$ & $\begin{array}{c}2.29[1.54- \\
3.39]^{* * *}\end{array}$ & 11 & $\begin{array}{c}1.87(0.80- \\
4.37)\end{array}$ & $\begin{array}{c}1.20(0.51- \\
2.86)\end{array}$ \\
\hline$>10$ cigs/day & 40 & $\begin{array}{c}4.21[1.93- \\
9.13]^{* * *}\end{array}$ & $\begin{array}{c}3.88[1.74- \\
8.67]^{* * *}\end{array}$ & 9 & $\begin{array}{c}4.04(1.07- \\
15.23) * *\end{array}$ & $\begin{array}{c}2.26(0.63- \\
8.05)\end{array}$ \\
\hline
\end{tabular}

For the alcohol consumption analysis, a ordinal logistic regression was performed, for abusive alcohol consumption analysis, a logistic regression was used with the reference are low and mid alcohol consumption. 
$* \mathrm{p}=0.05, * * \mathrm{p}=0.01, * * * \mathrm{p}<0.001$

$\mathrm{COR}=$ Crude Odds Ratios, $\mathrm{AOR}=$ Adjusted Odds Ratios.

Finally, we computed the risk of having abusive consumption in those consuming alcohol. Sex is an important risk factor with increased risk for the men compared to women (AOR $=2.53[1.38-4.68]$ ) as well as the occupational status with jobless people and housemaker associated with a decreased risk of having abusive consumption (AOR $=0.05[0.01-0.47]$ and $\mathrm{AOR}=0.14[0.02-0.78]$ respectively).

The risk also varied from the different regions, AORs for the different regions of the countries are presented in Table 4. We observed that the Sud-Ouest region has a higher risk of consumption compared to the rest of the country. In the Sahel, Est and Haut-Bassin, the risks of consumption are significantly lower.

Table 4: Risk of alcohol consumption in the different regions of the country.

\begin{tabular}{|l|l|l|l|}
\hline \multirow{2}{*}{ Region } & \multirow{2}{*}{$\mathrm{N}$} & \multicolumn{2}{|c|}{ Alcohol consumption } \\
\cline { 3 - 4 } & & $\mathrm{n}$ & AOR $(95 \% \mathrm{CI})$ \\
\hline Centre & 548 & 168 & Ref \\
\hline Boucle du Mouhoun & 469 & 147 & $1.23[0.63-2.39]$ \\
\hline Cascades & 166 & 45 & $0.58[0.28-1.19]$ \\
\hline Centre-Est & 398 & 72 & $0.51[0.24-1.06]$ \\
\hline Centre-Nord & 434 & 87 & $0.67[0.35-1.29]$ \\
\hline Centre-Ouest & 390 & 121 & $0.94[0.45-1.99]$ \\
\hline Centre-Sud & 217 & 51 & $0.66[0.28-1.54]$ \\
\hline Est & 376 & 63 & $0.40[0.22-0.74]^{* *}$ \\
\hline Haut-Bassin & 509 & 89 & $0.39[0.24-0.66]^{* * *}$ \\
\hline Nord & 420 & 72 & $0.66[0.28-1.58]$ \\
\hline Plateau Central & 236 & 62 & $1.01[0.37-2.75]$ \\
\hline Sahel & 315 & 4 & $0.02[0.01-0.15]^{* * *}$ \\
\hline Sud-Ouest & 214 & 148 & $5.63[1.98-16.01]^{* * *}$ \\
\hline
\end{tabular}

Model is adjusted for age, sex, living environment, education, marital status, occupational status and tobacco consumption.

$* \mathrm{p}=0.05, * * \mathrm{p}=0.01, * * * \mathrm{p}<0.001$

\section{Discussion}

We report here the results of the first nationally representative survey on the prevalence and risk factors for alcohol consumption in Burkina Faso.

The overall prevalence of people with abusive alcohol consumption is $2.7 \%$ [2.0 - 3.7]. This consumption is lower compared to other African countries [12] and the rest of the world [13]. This prevalence might be underestimated because even though Burkina Faso is a laic country, the majority of its inhabitants have a religious faith that prohibits alcohol consumption that could prevent some people from declaring their 
alcohol intake, this might be particularly truth in the Sahel region. In addition, alcohol consumption is blamed by society and could also lead to an under-declaration (positive social perception bias) [31].

We also found differences in the different regions of the country with the highest consumption found in the Sud-Ouest region. In this region almost each household produces local beer ('dolo') this might explain this observation. The income disparities and the alcohol availability between the different regions could explain those differences [32]. From a public health perspective this region also have the highest prevalence of Hepatitis B and C [33]. The inhabitants of these regions seem to cumulate the hepatotoxic risk of Hepatitis and alcohol consumption. We found a null prevalence in the Sahel region, this is an entirely Muslim region and the desirability bias may be more important compared to other region.

We also found gender differences with an increased risk in men compared to women for abusive alcohol consumption. It is important to specify here that, following the WHO guidelines, the thresholds used to define the different levels of alcohol consumption are different for men and women (33 to $50 \%$ lower for women compared to men).

In most countries, the prevalence is higher in men compared to women [17, 34], but when adjusting for multiple factors such as social supports and financial aspects, this effect seems less important. Compared to men, more women are lifetime abstainers, drink less, and are less likely to engage in problem drinking, develop alcohol-related disorders or alcohol withdrawal symptoms. However, women drinking excessively develop more medical problems. Biological (sex-related) factors, including differences in alcohol pharmacokinetics as well as its effect on brain function and the levels of sex hormones, may contribute to some of those differences [35]. Since pregnant women are particularly vulnerable, we performed sub-group analysis. A subgroup of 299 out of the 2,449 (12.2\%) women were pregnant during the survey, amongst them, $6(3.9 \%)$ reported alcohol consumption, which is statistically lower compared to non-pregnant women $(12.6 \%, p=.001)$.

Interestingly we observed that the age was significantly associated with alcohol consumption with a gradient effect of age on alcohol consumption but the risk of abusive consumption is not influenced by age. The influence of age on alcohol consumption is still unclear and not well documented in the literature, except for binge drinking, where young adults are the most at risk [36]. However, this result should be interpreted carefully, considering our study design. On the other hand, the results could be the results of preventive campaigns as reflected by a cohort effect A large Australian study including 7 crosssectional waves showed indeed that male cohorts born between the 1965 and 1974 and female cohorts born between 1955 and 1974 reported higher rates of drinking participation $(P<0.05)$, while the most recent cohorts (born in the 1990s) had lower rates of participation $(P<0.01)$ [37].

Concerning the risk of switching to an abusive consumption among drinkers only two factors have been identified: the risk in increased in male (as for the general consumption) and decreased with the occupational status, probably due to financial constraints. 
The association with tobacco consumption is probably one of the most important from a public health view because of the comorbidities and the double burden it presents for the population. In a previous study, we identified people most at risk of tobacco consumption in Burkina Faso: tobacco smoking among men was significantly associated with increased age and alcohol consumption. Analysis of risk factors for other tobacco use stratified by gender show that age, education, residence and alcohol consumption were significantly associated with consumption for women, age and alcohol consumption for men [24].

As recommended by the WHO, in this paper we presented risk factor associated to abusive alcohol consumption because of the proven negative effects. It is, however, interesting to note that from a medical point of view a limited and reasonable alcohol consumption could have some health related benefits: for example the relation between dementia and cognitive disorders is not linear and limited alcohol consumption has a protective role for dementia [38-40] or the protective effect of alcohol on cardio vascular risk, previously known as 'the French paradox' [41-43]. However, these results must be interpreted with caution, especially since it is known that even in low doses, alcohol consumption transiently increases the risk of cardiovascular accidents [44]. Another important point is that considering the prevention side experiences showed that adopting a too strong position by prohibiting any consumption or behavior will lead to poor results $[45,46]$. Considering these two aspects low alcohol consumption could be considered as acceptable.

The main limitation of this study is that alcohol (and tobacco) consumptions were obtained during interviews and is therefore dependent on the faith of the participants. There is therefore, both a risk of memory bias and social desirability, probably more marked during pregnancy. It can thus be estimated that the numbers and prevalence obtained in this survey underestimate the actual consumption. Another potential limitation is that some well-known risk factors for alcohol consumption were not included in the study because data on these variables have not been collected during the STEPS survey. Part of such variables is socioeconomic status. It is a transversal study; therefore there is a risk of survival bias indicating that elder participants with high consumption may die prematurely due to this consumption [47].

Despite these limitations, given the study design (cluster sampling design) and the sample size, the results of this study can be extended to the whole of Burkina Faso.

\section{Conclusion}

In this study, we reported on the burden of alcohol consumption and associated risk factors in a nationally representative sample of adults in Burkina Faso. Our data showed an important burden of alcohol consumption in Burkina Faso. Tobacco consumption is an important modifiable risk factor associated with alcohol consumption. Zone specific interventions are needed given the higher burden in urban centers and in some specific regions such as the Sud-Ouest region. Health policies in Burkina Faso must henceforth account for the control of alcohol and tobacco consumption since there is a strong 
relationship between those two important risk factors of NCDs. Alcohol policies that regulate the physical availability of alcohol are associated with lower alcohol consumption in low- and middle-income countries [48] and should, therefore, be implemented.

\section{List Of Abbreviation}

DHS: Demographic and Health Surveys

NCD: Non-communicable disease

SSA: sub-Saharan Africa

STEPS: WHO STEPwise approach to surveillance

WHO: World Health Organization

\section{Declarations}

\section{Ethics approval and consent to participate Consent for publication}

The protocol of the STEPS survey was reviewed and approved by the Ethics Committee for Health Research of the Ministry of Health of Burkina Faso, which gave clearance in accordance with regulations in force (Deliberation No. 2012-12- 092 of 05 December 2012). Written informed consent was systematically sought and obtained from all participants before inclusion in the study. The confidentiality of study participants was fully respected and the analyses performed did not identify any participant.

\section{Availability of data and materials}

The dataset of the STEPS survey that was used in this research is available at the Ministry of Health upon request. Any request to reanalyze the data can be directed to Dr Brice Bicaba.

\section{Acknowledgments}

The authors are thankful to all the people involved in the STEPS survey. Bruno Bonnechère thanks people who help him during the analysis of the data in Burkina Faso.

\section{Competing interests}

The authors declare that they have no competing interests.

\section{Funding}

Bonnechère Bruno received a travel grant from ARES (https://www.ares-ac.be/fr/) to conduct the data analysis in Burkina Faso (second analysis of the STEP survey), interpret the data with local epidemiologists and write the manuscript. Kadari Cissé is funded by ARES. 


\section{Authors' contributions}

BB and FKS conceived the study. BB, SS and CK proposed an early draft of the paper. FKS, SK, and ST made substantial contributions to the conception and design, analysis and interpretation of the data. KFS, KS and ST contributed significantly to revise the manuscript. All authors read and approved the final manuscript.

\section{References}

1. GBD 2015 DALYs and HALE Collaborators. Global, regional, and national disability-adjusted life-years (DALYs) for 315 diseases and injuries and healthy life expectancy (HALE), 1990-2015: a systematic analysis for the Global Burden of Disease Study 2015. Lancet Lond Engl. 2016;388:1603-58.

2. Lee I-M, Shiroma EJ, Lobelo F, Puska P, Blair SN, Katzmarzyk PT, et al. Effect of physical inactivity on major non-communicable diseases worldwide: an analysis of burden of disease and life expectancy. Lancet Lond Engl. 2012;380:219-29.

3. NCD Countdown 2030 collaborators. NCD Countdown 2030: worldwide trends in non-communicable disease mortality and progress towards Sustainable Development Goal target 3.4. Lancet Lond Engl. 2018;392:1072-88.

4. World Health Organization. World Health Statistics 2018: Monitoring health for the SDGs. 2018.

5. Jamison DT, Summers LH, Alleyne G, Arrow KJ, Berkley S, Binagwaho A, et al. Global health 2035: a world converging within a generation. Lancet Lond Engl. 2013;382:1898-955.

6. Kearney PM, Whelton M, Reynolds K, Muntner P, Whelton PK, He J. Global burden of hypertension: analysis of worldwide data. Lancet Lond Engl. 2005;365:217-23.

7. Whiteford HA, Degenhardt L, Rehm J, Baxter AJ, Ferrari AJ, Erskine HE, et al. Global burden of disease attributable to mental and substance use disorders: findings from the Global Burden of Disease Study 2010. Lancet Lond Engl. 2013;382:1575-86.

8. Afshin A, Micha R, Webb M, Capewell S, Whitsel L, Rubinstein A, et al. Effectiveness of Dietary Policies to Reduce Noncommunicable Diseases. In: Prabhakaran D, Anand S, Gaziano TA, Mbanya JC, Wu Y, Nugent R, editors. Cardiovascular, Respiratory, and Related Disorders. 3rd edition. Washington (DC): The International Bank for Reconstruction and Development / The World Bank; 2017. http://www.ncbi.nlm.nih.gov/books/NBK525147/. Accessed 10 Sep 2019.

9. Juma PA, Mohamed SF, Matanje Mwagomba BL, Ndinda C, Mapa-Tassou C, Oluwasanu M, et al. Non-communicable disease prevention policy process in five African countries. BMC Public Health. 2018;18 Suppl 1:961.

10. Shield K, Manthey J, Rylett M, Probst C, Wettlaufer A, Parry CDH, et al. National, regional, and global burdens of disease from 2000 to 2016 attributable to alcohol use: a comparative risk assessment study. Lancet Public Health. 2020;5:e51-61.

11. Manthey J, Shield KD, Rylett M, Hasan OSM, Probst C, Rehm J. Global alcohol exposure between 1990 and 2017 and forecasts until 2030: a modelling study. The Lancet. 2019;393:2493-502. 
12. World Health Organization. Global Status Report on Alcohol and Health-2014. 2014.

13. Shield KD, Rylett M, Gmel G, Gmel G, Kehoe-Chan TAK, Rehm J. Global alcohol exposure estimates by country, territory and region for 2005--a contribution to the Comparative Risk Assessment for the 2010 Global Burden of Disease Study. Addict Abingdon Engl. 2013;108:912-22.

14. Clausen T, Rossow I, Naidoo N, Kowal P. Diverse alcohol drinking patterns in 20 African countries. Addict Abingdon Engl. 2009;104:1147-54.

15. Reuters. SABMiller Eyes Africa \$2.5bn Investment. 2012. http://www.iol.co.za/business/international/sabmiller-eyes-africa-25bn-investment-1277086. Accessed $8 \mathrm{Jul} 2019$.

16. African Business. Alcohol Consumption Rising in Africa Despite Obstacles. https://africanbusinessmagazine.com/sectors/retail/alcohol-consumption-rising-in-africa-despiteobstacles/. Accessed 8 Jul 2019.

17. Chaiyasong S, Huckle T, Mackintosh A-M, Meier P, Parry CDH, Callinan S, et al. Drinking patterns vary by gender, age and country-level income: Cross-country analysis of the International Alcohol Control Study. Drug Alcohol Rev. 2018;37 Suppl 2:S53-62.

18. Huckle T, Romeo JS, Wall M, Callinan S, Holmes J, Meier P, et al. Socio-economic disadvantage is associated with heavier drinking in high but not middle-income countries participating in the International Alcohol Control Study. Drug Alcohol Rev. 2018;37 Suppl 2:S63-71.

19. Martinez P, Røislien J, Naidoo N, Clausen T. Alcohol abstinence and drinking among African women: data from the World Health Surveys. BMC Public Health. 2011;11:160.

20. Popova S, Lange S, Probst C, Shield K, Kraicer-Melamed H, Ferreira-Borges C, et al. Actual and predicted prevalence of alcohol consumption during pregnancy in the WHO African Region. Trop Med Int Health TM IH. 2016;21:1209-39.

21. Sanou AS, Diallo AH, Holding P, Nankabirwa V, Engebretsen IMS, Ndeezi G, et al. Maternal alcohol consumption during pregnancy and child's cognitive performance at 6-8 years of age in rural Burkina Faso: an observational study. PeerJ. 2017;5:e3507.

22. Mosdø| A, Lidal IB, Straumann GH, Vist GE. Targeted mass media interventions promoting healthy behaviours to reduce risk of non-communicable diseases in adult, ethnic minorities. Cochrane Database Syst Rev. 2017;2:CD011683.

23. Soubeiga JK, Millogo T, Bicaba BW, Doulougou B, Kouanda S. Prevalence and factors associated with hypertension in Burkina Faso: a countrywide cross-sectional study. BMC Public Health. 2017;17:64.

24. Bonnechère B, Cissé K, Millogo Tiéba, Ouédraogo H. Gautier, Garanet Franck, Ouedraogo Adja Mariam, et al. Tobacco use and associated risk factors in Burkina Faso: Results from a nationwide population-based survey. BMC Public Health. 2019.

25. Institut National de la Statistique et de la Démographie (INSD); ICF International. Enquête Démographique et de Santé et à Indicateurs Multiples du Burkina Faso 2010. 2012. 
26. Ministère de la santé du Burkina Faso. Rapport de l'enquête nationale sur la prévalence des principaux facteurs de risque communs aux maladies non transmissibles (STEPS 2013). 2014.

27. Bonnet $E$, Lechat $L$, Ridde $V$. What interventions are required to reduce road traffic injuries in Africa? $A$ scoping review of the literature. PloS One. 2018;13:e0208195.

28. WHO. STEPwise approach to chronic disease risk factor surveillance. https://www.who.int/ncds/surveillance/steps/burkina_faso/en/.

29. Millogo T, Bicaba BW, Soubeiga JK, Dabiré E, Médah I, Kouanda S. Diabetes and abnormal glucose regulation in the adult population of Burkina Faso: prevalence and predictors. BMC Public Health. 2018;18. doi:10.1186/s12889-018-5257-4.

30. Kendagor A, Gathecha G, Ntakuka MW, Nyakundi P, Gathere S, Kiptui D, et al. Prevalence and determinants of heavy episodic drinking among adults in Kenya: analysis of the STEPwise survey, 2015. BMC Public Health. 2018;18:1216.

31. Jemmott JB, Ditto PH, Croyle RT. Judging health status: effects of perceived prevalence and personal relevance. J Pers Soc Psychol. 1986;50:899-905.

32. Dixon MA, Chartier KG. Alcohol Use Patterns Among Urban and Rural Residents: Demographic and Social Influences. Alcohol Res Curr Rev. 2016;38:69-77.

33. Meda N, Tuaillon E, Kania D, Tiendrebeogo A, Pisoni A, Zida S, et al. Hepatitis B and C virus seroprevalence, Burkina Faso: a cross-sectional study. Bull World Health Organ. 2018;96:750-9.

34. Takahashi R, Wilunda C, Magutah K, Mwaura-Tenambergen W, Wilunda B, Perngparn U. Correlates of alcohol consumption in rural western Kenya: A cross-sectional study. BMC Psychiatry. 2017;17:175.

35. Erol A, Karpyak VM. Sex and gender-related differences in alcohol use and its consequences: Contemporary knowledge and future research considerations. Drug Alcohol Depend. 2015;156:1-13.

36. Kuntsche E, Kuntsche S, Thrul J, Gmel G. Binge drinking: Health impact, prevalence, correlates and interventions. Psychol Health. 2017;32:976-1017.

37. Livingston M, Raninen J, Slade T, Swift W, Lloyd B, Dietze P. Understanding trends in Australian alcohol consumption-an age-period-cohort model. Addict Abingdon Engl. 2016;111:1590-8.

38. Heffernan M, Mather KA, Xu J, Assareh AA, Kochan NA, Reppermund S, et al. Alcohol Consumption and Incident Dementia: Evidence from the Sydney Memory and Ageing Study. J Alzheimers Dis JAD. 2016;52:529-38.

39. Xu W, Wang H, Wan Y, Tan C, Li J, Tan L, et al. Alcohol consumption and dementia risk: a doseresponse meta-analysis of prospective studies. Eur J Epidemiol. 2017;32:31-42.

40. Gutwinski S, Schreiter S, Priller J, Henssler J, Wiers CE, Heinz A. Drink and Think: Impact of Alcohol on Cognitive Functions and Dementia - Evidence of Dose-Related Effects. Pharmacopsychiatry. 2018;51:136-43.

41. O'Keefe JH, Bhatti SK, Bajwa A, DiNicolantonio JJ, Lavie CJ. Alcohol and cardiovascular health: the dose makes the poison...or the remedy. Mayo Clin Proc. 2014;89:382-93. 
42. Fernández-Solà J. Cardiovascular risks and benefits of moderate and heavy alcohol consumption. Nat Rev Cardiol. 2015;12:576-87.

43. Rehm J, Roerecke M. Cardiovascular effects of alcohol consumption. Trends Cardiovasc Med. 2017;27:534-8.

44. Mostofsky E, Chahal HS, Mukamal KJ, Rimm EB, Mittleman MA. Alcohol and Immediate Risk of Cardiovascular Events: A Systematic Review and Dose-Response Meta-Analysis. Circulation. 2016;133:979-87.

45. Cyril S, Smith BJ, Renzaho AMN. Systematic review of empowerment measures in health promotion. Health Promot Int. 2016;31:809-26.

46. Gelius $P$, Rütten A. Conceptualizing structural change in health promotion: why we still need to know more about theory. Health Promot Int. 2018;33:657-64.

47. Roerecke M. On bias in alcohol epidemiology and the search for the perfect study. Addict Abingdon Engl. 2017;112:217-8.

48. Cook WK, Bond J, Greenfield TK. Are alcohol policies associated with alcohol consumption in lowand middle-income countries? Addict Abingdon Engl. 2014;109:1081-90.

\section{Figures}

Total sample surveyed

$$
n=4,800
$$

Missing data on alcohol consumption

$$
n=0
$$

\section{Obserations with valid data}

$$
n=4,800
$$

\section{Missing data on sampling weights}

$$
n=108
$$

\section{Obserations with valid data

$$
n=4,692
$$


Figure 1

Consort Diagram describing study participants, exclusions and analytic sample size.

\section{Prevalence of alcohol consumption in Burkina Faso}

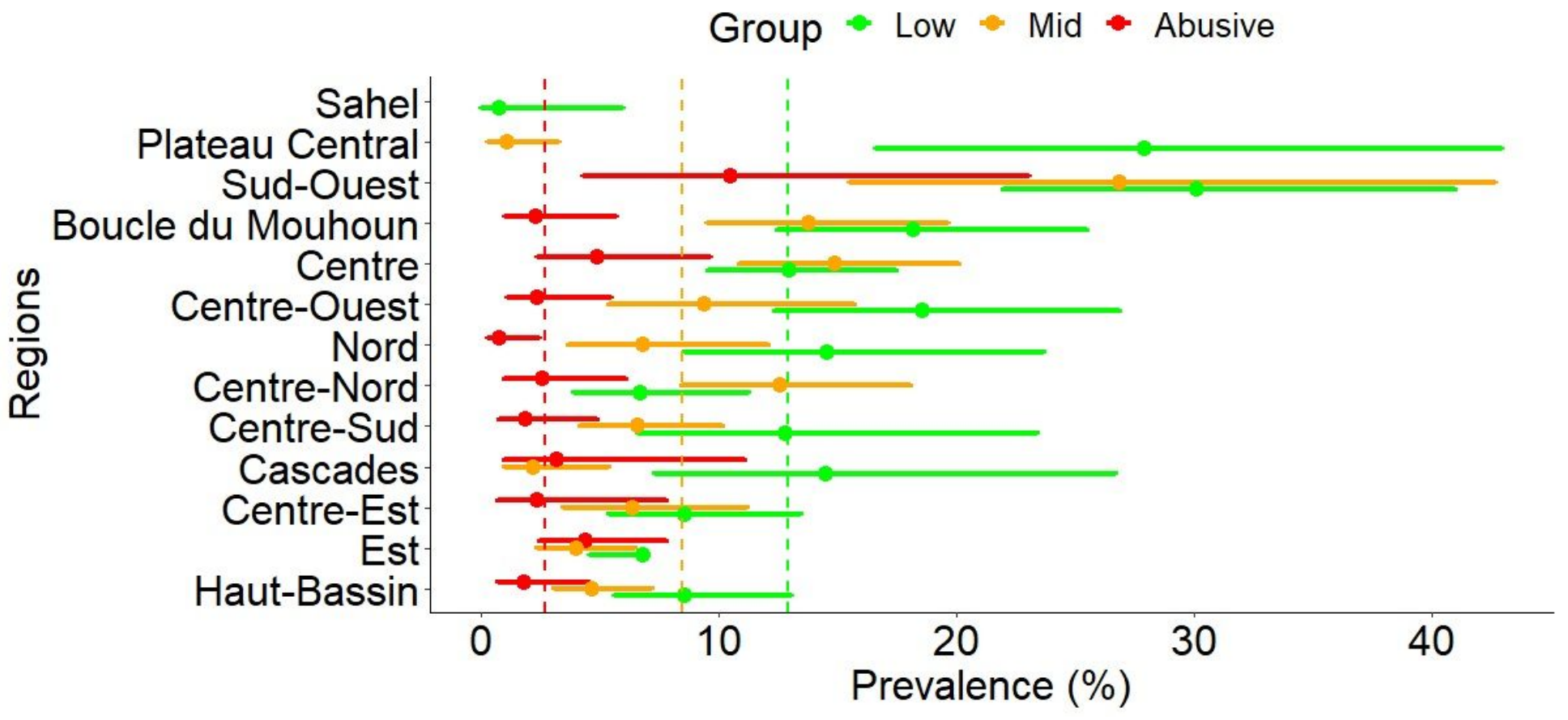

Figure 2

Prevalence of the level of alcohol consumption in the different regions of Burkina Faso. Vertical lines indicate the mean prevalence for the whole country.

Adjusted OR (compared to Ouagadougou) for alcohol consumption in the different region of Burkina-Faso

$<0.50$

$0.51-0.99$

Reference value

$1.01-1.5$

$>1.50$

Source: STEPS

Burkina-Faso (2013)

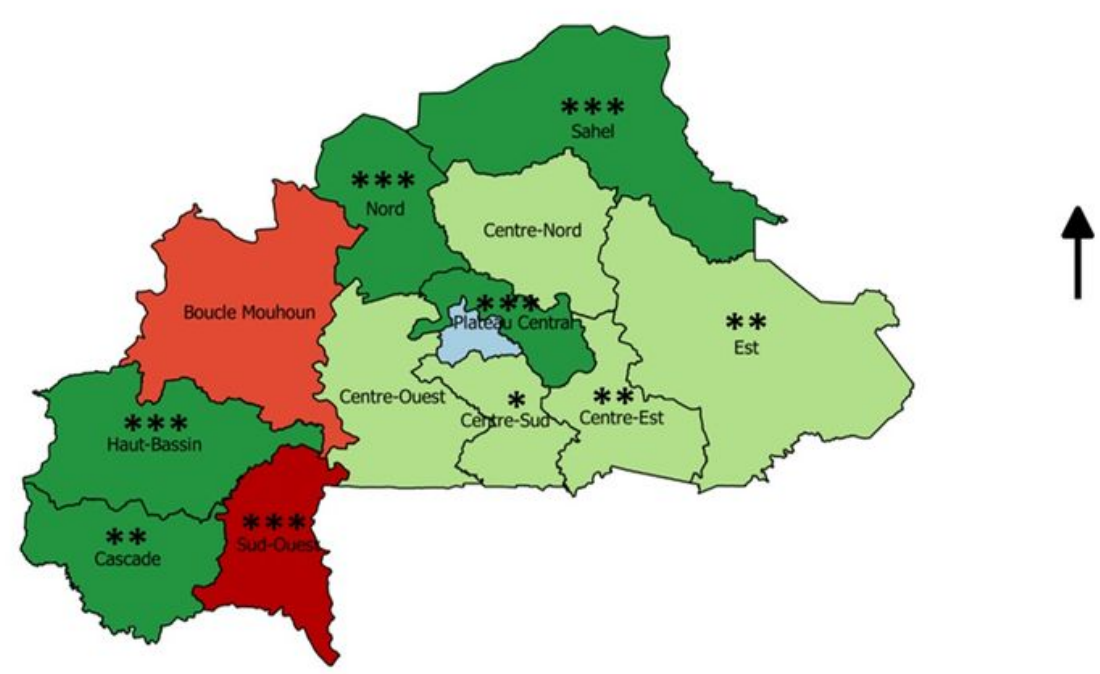

$\begin{array}{lllllll}100 & 0 & 100 & 200 & 300 & 400 & \mathrm{~km}\end{array}$ 


\section{Figure 3}

OR Adjusted for age, education, marital status, occupational status and tobacco consumption for alcohol consumption compared to the center region for the whole population * indicates statistically significant differences. Raw map has been downloaded and used with permission from GADM (https://gadm.org/) and updated with the result of this analysis.

\section{Supplementary Files}

This is a list of supplementary files associated with this preprint. Click to download.

- STROBEAlcohol.doc 